\title{
Thermal Radiation and Variable Pressure Effects on Natural Convective Heat and Mass Transfer Fluid Flow in Porous Medium
}

\author{
${ }^{1}$ B. Y. Isah, ${ }^{* 2}$ M. M. Altine and ${ }^{1 S}$. K. Ahmad \\ ${ }^{1}$ Department of Mathematics, Usmanu Danfodiyo University, Sokoto, Nigeria \\ 2Department of Mathematics, Federal University Birnin Kebbi, Nigeria \\ ["Corresponding Author: E-mail: altinemuhammad@gmail.com; D: 08064819725]
}

\begin{abstract}
The study investigates the interaction of free convective flow with thermal radiation and variable pressure on natural convective heat and mass transfer fluid flow in porous medium. Solutions for time dependent energy, concentration and momentum equations were obtained by the perturbation series method after transforming into ordinary differential equations. The effect of various flow parameters such as: suction/injection $(\delta)$, radiation $(R)$, magnetic field $(M)$, heat source $(S)$, chemical reaction $(R c)$ on the skin friction, rate of heat transfer, velocity, temperature, and concentration profile influencing the physical situation were discussed with the aid of line graphs.
\end{abstract}

Keywords: Thermal Radiation, Variable pressure, Perturbation, Natural Convection

\section{INTRODUCTION}

Radiation effects on heat and mass transfer are of greater importance in many processes and have therefore, received a considerable attention in recent time. It is applied in engineering fields and physiology such as transpiration, cooling gaseous diffusion and blood flow in arteries. Radiative heat and mass transfer play important roles in the design of spacecraft, filtrations processes, the drying of porous material in textiles industries, solar energy collector and nuclear reactors (Ahmad et al., 2014). Chandra et al. (2014) studied unsteady MHD free convection flow along a vertical plate in the presence of radiation heat flux. Das et al. (2011) reported radiation effect on natural convection near a vertical plate embedded in porous medium with ramped wall temperature. Das et al. (1966) investigated radiation effect on flow past an impulsively started vertical plate. Das and Jana (2010) studied the heat and mass transfer effects on unsteady MHD free convection flow near a moving vertical plate on porous medium. Hossain and Takhar (2010) examined radiation effect on mixed convection along a vertical plate with uniform surface temperature. Hossain et al. (1999) studied the effect of radiation on free convection from a porous vertical plate. Ibrahim et al. (2008) studied the effect of chemical reaction and radiation absorption on the unsteady MHD free convection flow passes a semi-infinite vertical permeable moving plate with heat source and suction. Javaherdeh et al. (2015) investigated natural convection heat and mass transfer in MHD fluid flow past a moving vertical plate with variable surface temperature and concentration in a porous medium. Jha et al. (2010) reported unsteady natural convection flow between infinite vertical parallel plates with ramped temperature. Jha et al. (2012) studied natural convection flow of heat generating/absorbing fluid near a vertical plate with ramped temperature. Kesavaiah et al. (2011) reported effect of the chemical reaction and radiation absorption on an unsteady MHD convective heat and mass transfer flow past a semi-infinite vertical permeable moving plate embedded in a porous medium with heat source and suction. Ishore et al. (2012) investigated the effects of thermal radiation and viscous dissipation on MHD heat and mass diffusion flow past an oscillating vertical plate embedded in a porous medium with variable surface conditions. Makinde et al. (2005) studied free convection flow with thermal radiation and mass transfer past a moving vertical porous plate. Djam and Manjak 
(2013) analyzed the effect of radiation on free convection flow due to heat and mass transfer through a porous medium bounded by two vertical walls. Mohamed (2009) reported the double diffusive conviction-radiation interaction on unsteady MHD flow over a vertical moving porous plate with heat generation and Soret effect. Pal and Talukdar (2010) investigated the perturbation analysis of unsteady magneto hydrodynamic convective heat and mass transfer in a boundary layer slip flow past a vertical permeable plate with thermal radiation and chemical reaction. Ramachandra et al. (2013) reported radiation and mass transfer effect on two-dimensional flow past an impulsively started infinite vertical plate. Rout et al. (2014) revealed effect radiation and chemical reaction on natural convective MHD flow through a porous medium with double diffusion. Singh (1986) studied effects of heat source/sink and irradiative heat transfer on hydromagnetic natural convective flow through a vertical channel. Sudheer and Satya (2009) analyzed effects of the chemical reaction and radiation absorption on free convection flow through porous medium with variable suction in the presence of uniform magnetic field.

The aim of this paper is to study thermal radiation effect on natural convective heat and mass transfer fluid flow in porous medium with the presence of variable pressure.

\section{MATHEMATICAL ANALYSES}

Consider the natural convective heat and mass transfer fluid flow in the presence of variable pressure in a porous medium. The flow is assumed to be in $x^{\prime}$ direction, which is taken along the vertical plate in upward direction, and $y^{\prime}$ axis is taken to be normal to the plate.

\section{NOMENCLATURE}

\begin{tabular}{ll}
$B_{0}$ External magnetic field & $\theta_{w}$ Constant temperature at the plate \\
$C$ Dimensionless concentration & $\theta^{\prime}$ Dimensional temperature of the fluid \\
$C^{\prime}$ Dimensional concentration of the fluid & $\delta$ Suction \\
$C_{w}^{\prime}$ Constant concentration at the plate & $C_{0}^{\prime}$ Initial concentration of the fluid \\
$G r$ Thermal Grashof number & $R_{c}$ Chemical reaction \\
$g$ Acceleration due to gravity & $T^{\prime}$ Dimensional fluid Temperature \\
$M$ Magnetic parameter & $C_{p}$ Specific heat at constant pressure \\
$N$ Suspension parameter & $T_{0}^{\prime}$ Dimensional initial temperature of the fluid \\
Pr Prandtl number & $h$ Gap between the plate \\
$Q$ Dimensional heat generation term & $\beta$ Volumetric coefficient of thermal expansion \\
$R$ Chemical reaction parameter & $\sigma$ Stefan Boltzmann constant (electrical \\
$S$ Dimensionless heat sink parameter & Conductivity) \\
$S c$ Schmidt number & $N u_{0}$ Nusselt number \\
$t$ Dimensionless time & $S h_{0}$ Sherwood number \\
$t_{0}$ Characteristic time & Greek symbols \\
$t^{\prime}$ Dimensional time & $v$ Kinematic viscosity \\
$U$ Dimensionless velocity of the fluid & $\rho$ Density of the fluid \\
$U^{\prime}$ Dimensional velocity of the fluid & $\theta$ Fluid Temperature \\
$y$ Dimensionless co-ordinate perpendicular & $v$ Kinematic viscosity \\
to the plate & $\beta$ Volumetric coefficient of thermal expansion \\
$y^{\prime}$ Dimensional co-ordinate to the plate & $\tau_{0}$ Skin friction \\
\hline
\end{tabular}


Initially, the temperature of the fluid and plate are same at temperature $T_{w}^{\prime}$ in the stationary condition and the concentration of the fluid is $C_{w}^{\prime}$. Where $\theta_{\infty}^{\prime}$ and $C_{\infty}^{\prime}$ are the temperature and concentration of the fluid far away from the plate. A magnetic field of uniform strength $B_{0}$ is applied normal to the plate in presence of radiative heat flux. See Figure 1.

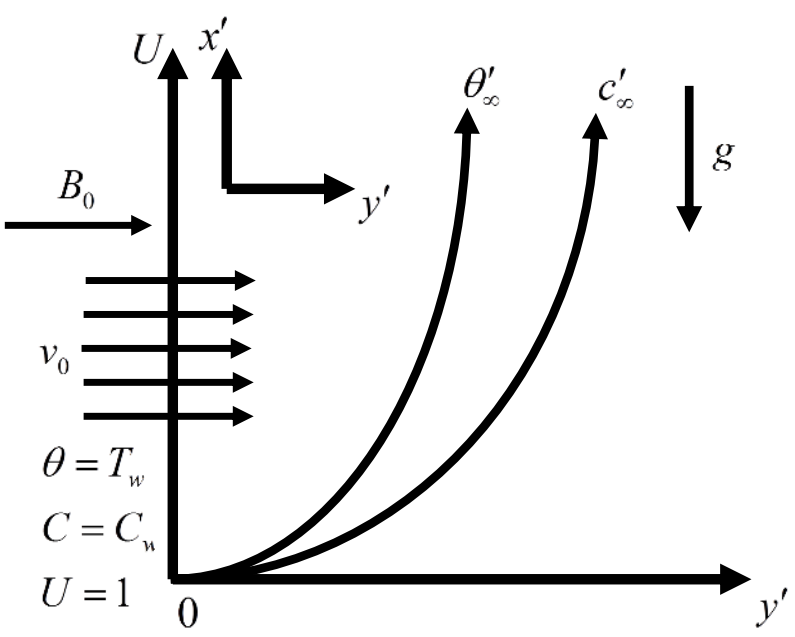

Figure 1: Flow configuration of the problem

Then under the usual Boussinesq's shown to be governed by the following system of approximation, the flow of a radiating fluid is equations:

$$
\begin{aligned}
& \frac{\partial U^{\prime}}{\partial t^{\prime}}+V^{\prime} \frac{\partial U^{\prime}}{\partial y^{\prime}}=v \frac{\partial^{2} U^{\prime}}{\partial y^{\prime 2}}+\frac{1}{\rho} \frac{\partial p}{\partial x}-\frac{\sigma B_{0}^{2} U^{\prime}}{\rho}-\frac{v}{K^{*}} U^{\prime}+g \beta\left(T^{\prime}-T_{\infty}^{\prime}\right)+g \beta^{*}\left(C^{\prime}-C_{\infty}^{\prime}\right) \\
& \frac{\partial \theta^{\prime}}{\partial t^{\prime}}+v^{\prime} \frac{\partial \theta^{\prime}}{\partial y^{\prime}}=\frac{K}{\rho C p} \frac{\partial^{2} \theta^{\prime}}{\partial y^{\prime 2}}+\frac{Q_{1}}{\rho C p}\left(T^{\prime}-T_{\infty}^{\prime}\right)-\frac{1}{\rho C p} \frac{\partial q_{r}}{\partial y^{\prime}} \\
& \frac{\partial C^{\prime}}{\partial t^{\prime}}+V^{\prime} \frac{\partial C^{\prime}}{\partial y^{\prime}}=D \frac{\partial^{2} C^{\prime}}{\partial y^{\prime 2}}
\end{aligned}
$$

The relevant initial and boundary condition for the present physical situation are:

$$
\begin{gathered}
t \leq 0, U^{\prime}=0, T^{\prime} \rightarrow T_{\infty}^{\prime}, C^{\prime} \rightarrow C_{\infty}^{\prime} \text { for all } y^{\prime} \\
t>0, U^{\prime}=0, T^{\prime}=T_{w}^{\prime}, C^{\prime}=C_{w}^{\prime} \text { at } y^{\prime}=0 \\
U^{\prime}=0, T^{\prime} \rightarrow T_{\infty}^{\prime}, C^{\prime} \rightarrow C_{\infty}^{\prime} \text { as } y^{\prime} \rightarrow \infty
\end{gathered}
$$

The dimensionless quantities introduced in the above equations are defined as: 


$$
\begin{aligned}
& U=\frac{U^{\prime}}{U_{0}}, y=\frac{y^{\prime} U_{0}}{v}, t=\frac{t^{\prime}}{t_{0}}, \theta=\frac{T^{\prime}-T_{\infty}^{\prime}}{T_{w}^{\prime}-T_{\infty}^{\prime}}, C=\frac{C^{\prime}-C_{\infty}^{\prime}}{C_{w}^{\prime}-C_{\infty}^{\prime}}, \\
& P_{r}=\frac{K}{\mu C p}, M=\frac{\sigma B_{0}^{2} v}{\rho U_{0}^{2}}, G r=\frac{g \beta v\left(T_{w}^{\prime}-T_{\infty}^{\prime}\right)}{U_{0}^{2}}, S c=\frac{v}{D}, \\
& N=\frac{g \beta_{1} v\left(C_{w}^{\prime}-C_{\infty}^{\prime}\right)}{U_{0}^{2}}, S=\frac{Q_{1} v}{\rho C p U_{0}^{2}}, \delta=\frac{V_{0}}{U_{0}}, R=\frac{16 a R^{*} \sigma T^{\prime 3}}{\alpha V_{0}^{2}},
\end{aligned}
$$

Substituting equation (5) into equation (1) - (4), the dimensionless boundary layer equations are:

$$
\begin{aligned}
& \frac{\partial U}{\partial t}+\delta \frac{\partial U}{\partial y}=\frac{\partial^{2} U}{\partial y^{2}}-\lambda \varepsilon e^{i \omega t}-M^{2} U-K U+G r \theta+N C \\
& \frac{\partial \theta}{\partial t}+\delta \frac{\partial \theta}{\partial y}=\frac{1}{\operatorname{Pr}} \frac{\partial^{2} \theta}{\partial y^{2}}-\frac{R \theta}{\operatorname{Pr}}+S \theta \\
& \frac{\partial C}{\partial t}+\delta \frac{\partial C}{\partial y}=\frac{1}{S c} \frac{\partial^{2} C}{\partial y^{2}}
\end{aligned}
$$

with the initial and boundary conditions

$$
\begin{aligned}
& t \leq 0, U=\theta=C=0 \text { for all } y \\
& t>0, U=1, \theta=1+\varepsilon e^{i w t}+\varepsilon^{2} e^{2 i w t}, C=1+\varepsilon e^{i w t}+\varepsilon^{2} e^{2 i w t} \text { at } y=0 \\
& U=0, \theta=0, C=0 \text { as } y \rightarrow \infty
\end{aligned}
$$

The solution to the dimensionless partial differential equations set in equations (6) to (9) can be obtained by representing velocity; temperature and mass transfer as follows:

$$
\begin{aligned}
& U=U_{0}+U_{1} \varepsilon e^{i w t}+U_{2} \varepsilon^{2} e^{2 i w t}+0\left(\varepsilon^{3}\right)+\cdots=\sum_{j=0}^{\infty} \varepsilon^{j} U_{j} e^{j(i w t)} \\
& \theta=\theta_{0}+\theta_{1} \varepsilon e^{i w t}+\theta_{2} \varepsilon^{2} e^{2 i w t}+0\left(\varepsilon^{3}\right)+\cdots=\sum_{j=0}^{\infty} \varepsilon^{j} \theta_{j} e^{j(i w t)} \\
& C=C_{0}+C_{1} \varepsilon e^{i w t}+C_{2} \varepsilon^{2} e^{2 i w t}+0\left(\varepsilon^{3}\right)+\cdots=\sum_{j=0}^{\infty} \varepsilon^{j} C_{j} e^{j(i w t)}
\end{aligned}
$$

The solutions of equations (6) - (8) under the initial and boundary conditions (9) by perturbation technique, and equating like powers of $\varepsilon$, the harmonic and non-harmonic boundary value problem for velocity, temperature and concentration equations are obtained as: 


$$
\begin{aligned}
& U(y)=B_{14} e^{-m_{14} y}+B_{15} e^{-m_{8} y}+B_{16} e^{-m_{2} y}+\varepsilon\left(B_{17} e^{m_{15} y}+B_{18} e^{-m_{16} y}+B_{19}+B_{20} e^{-m_{10} y}+B_{21} e^{-m_{4} y}\right) e^{i w t} \\
& +\varepsilon^{2}\left(B_{23} e^{-m_{18} y}+B_{24} e^{-m_{12} y}+B_{25} e^{-m_{6} y}\right) e^{2 i w t} \\
& \theta(y)=e^{-m_{8} y}+\varepsilon e^{i w t} e^{-m_{10} y}+\varepsilon^{2} e^{2 i w t} e^{-m_{12} y} \\
& C(y)=e^{-m_{2} y}+\varepsilon e^{i w t} e^{-m_{4} y}+\varepsilon^{2} e^{2 i w t} e^{-m_{6} y}
\end{aligned}
$$

Using equation (11) the skin friction on the plate at $\mathrm{y}=0$ is:

$$
\begin{aligned}
& \tau_{0}=\left.\frac{d U}{d y}\right|_{y=0}=-m_{14} B_{14}-m_{8} B_{15}-m_{2} B_{16}+\varepsilon\left(m_{15} B_{17}-m_{16} B_{18}-m_{10} B_{20}-m_{4} B_{21}\right) e^{i w t} \\
& +\varepsilon^{2}\left(-m_{18} B_{23}-m_{12} B_{24}-m_{6} B_{25}\right) e^{2 i w t}
\end{aligned}
$$

Using equation (12) the rate of heat transfer on the plate at $y=0$ is:

$N u_{0}=\frac{d \theta}{d y}{ }_{y=0}=-m_{8}-\varepsilon e^{\text {svt }} m_{10}-\varepsilon^{2} e^{2 \text { sivt }} m_{12}$

Using equation (13) the Sherwood number on the plate at $y=0$ is obtained as:

$$
S h_{0}=\left.\frac{d C}{d y}\right|_{y=0}=-m_{2}-\varepsilon e^{i v t} m_{4}-\varepsilon^{2} e^{2 i w t} m_{6}
$$

It is important to note that the constants, $B_{i s}$ and $m_{i s}$ were not presented here.

\section{RESULTS AND DISCUSSION}

The numerical values of the velocity $(U)$, temperature $(\theta)$ concentration $(C)$, skin-friction $(\tau)$ Nusselt number $(\mathrm{Nu})$ and Sherwood number $(S h)$ are computed for different parameters such as: Prandtl number $(\mathrm{Pr})$, Schmidt number $(S c)$, magnetic parameter $(M)$, thermal Grashof number $(\mathrm{Gr})$, sustention parameter $(N)$, permeability parameter $(K)$, suction/injection parameter $(\delta)$ and chemical reaction parameter $(R c)$. The values are chosen for: $\operatorname{Pr}=0.71$ (for air) and $\operatorname{Pr}=7.0$ (for water) while $S c=0.60 \quad$ (for Oxygen), $0.78 \quad$ (for Ammonia) and 2.01 (for Ethyl Benzene). $\mathrm{Gr}>0$ (for cooling of the plate) and $\mathrm{Gr}<0$ (for heating of the plate). The velocity, temperature and concentration profiles for different parameters $\operatorname{Pr}, R c, M, \quad R, S, S c, K, \delta, G r \quad$ and $N$ are presented in Figures 2 to 8 . The numerical values for skin-friction, Nusselt number and Sherwood number are shown in table 1.

Figures $2 a$ and $b$ reflect the effect of thermal radiation parameter on velocity, as $R$ increases the velocity of the fluid decreases; this is due to the fact that increases in thermal radiation parameter lead to higher convectional current. It is noticed from Figure $2 b$ that thermal radiation 
parameter is higher in case of injection than suction, suction and injection increases resistance to the flow resulting in decrease in the flow velocity. As shown in Figure $2 \mathrm{~b}$. However the velocity decreases for $\mathrm{Gr}>0$ but reverse effect is observed for $G r<0$. Figure 3 depict that the velocity profile decreases with increase in Schmidt number $(S c)$. From Figure 4, it can be observed that the velocity increases with increasing values of thermal Grashof number(Gr). This is possible because $\mathrm{Gr}$ enhances buoyancy force, the positive values of $\mathrm{Gr}$ indicate the cooling plate and it is observed that velocity increases rapidly near the wall of the plate and then decays to the free stream velocity. In Figure 5, it can be seen that magnetic field parameter retards the fluid flow because the presence of transverse magnetic fluid produces a resistive force or a drag force called a Lorentz force, which slows down the motion of electronically conducting fluid. It is seen from Figure $5 a$ and $b$ that the velocity is higher in

a

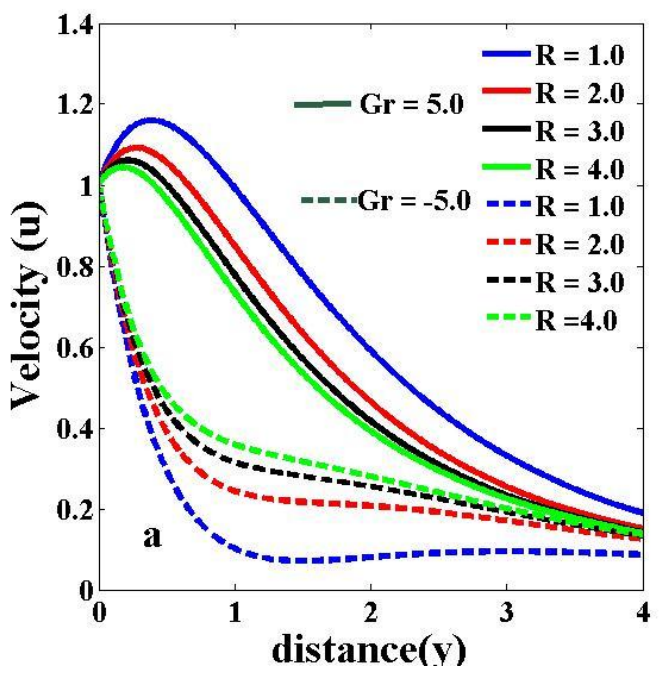

injection $(\delta>0)$ than suction $(\delta<0)$. From Figure 6 it is observed that the temperature decreases with increase in radiation parameter, the temperature is higher incase of injection than suction. It can noticed from Figure 7 that the temperature increases with increase in heat source parameter by fixing other physical parameters and the temperature is higher incase of injection than suction. Figure 8 shows that when thermal radiation parameter increases, the fluid temperature decreases, the effect of thermal radiation parameter is more significant in case of air $(P r=0.71)$ than water $(P r=7.0)$ as shown in Figure $8 a$ and $b$. This is due to the physical fact that as the Prandtl number increases the thermal diffusivity of the fluid decreases. In Figure $9 a$ and $b$, it is observed that increasing $R c$ and $S c$ decreases the concentration. However values of concentration are high with $S c$ in comparison with $R c$. In addition concentration increases with $\delta>0$ and decreases with $\delta<0$.

b

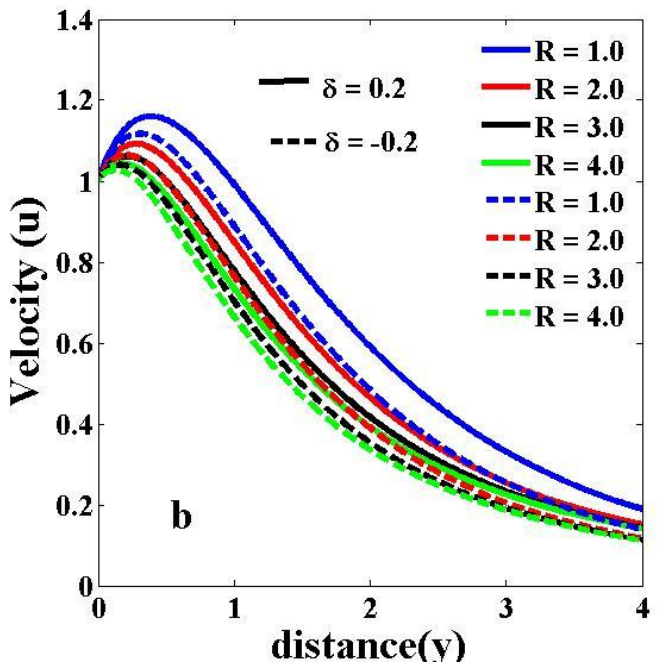

Figure 2: Effect of radiation parameter $(R)$, on velocity $(u)$. 
Nigerian Journal of Basic and Applied Science (June, 2019), 27(1): 48-58

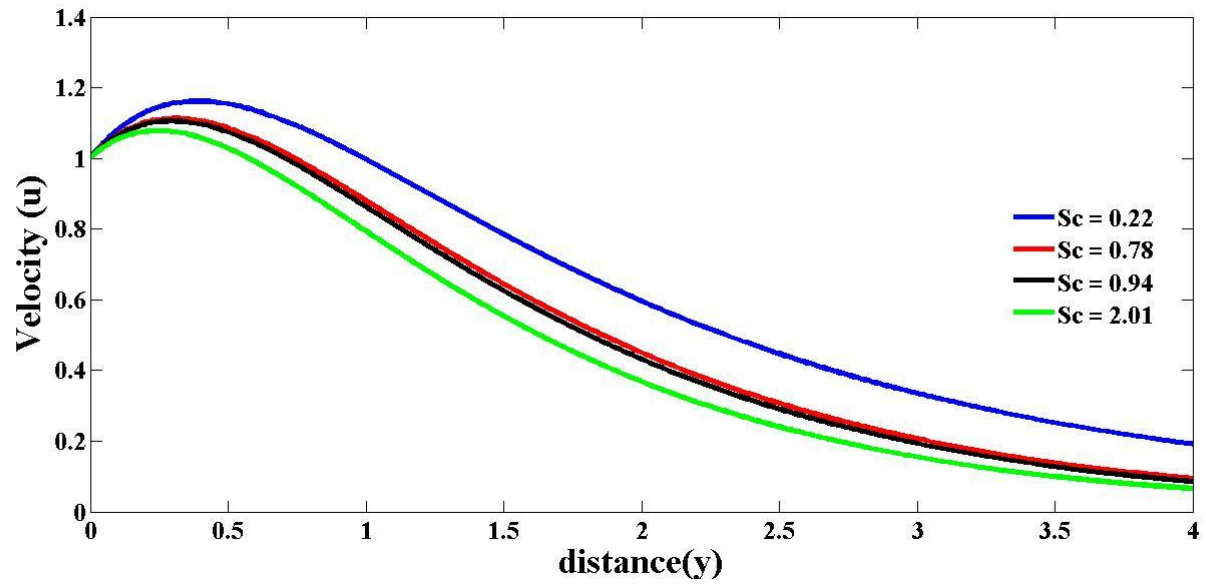

Figure 3: Effect Schmidt number $(S c)$ on velocity $(v)$

a

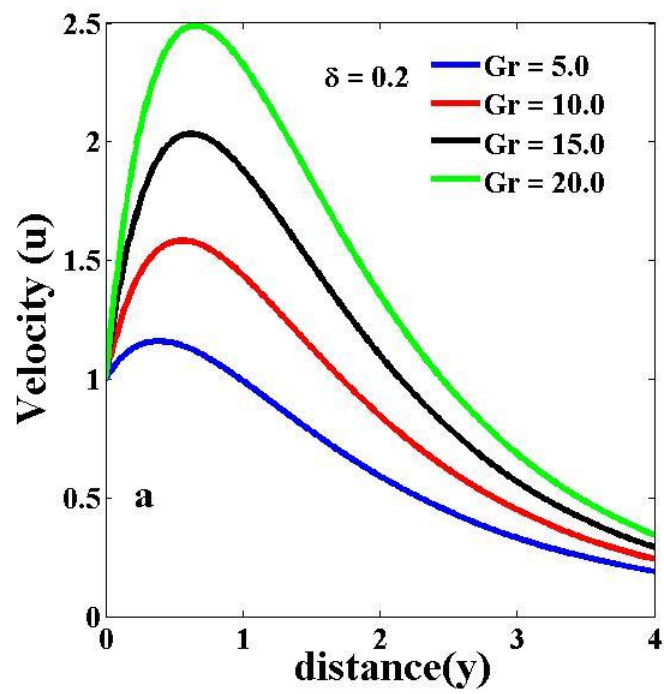

b

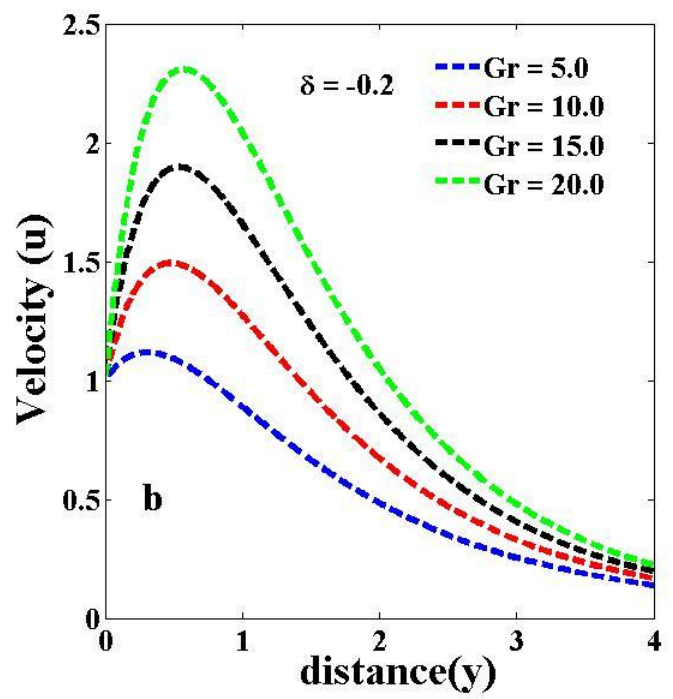

Figure 4: Effect of thermal Grashof number $(G r)$, on velocity $(u)$.
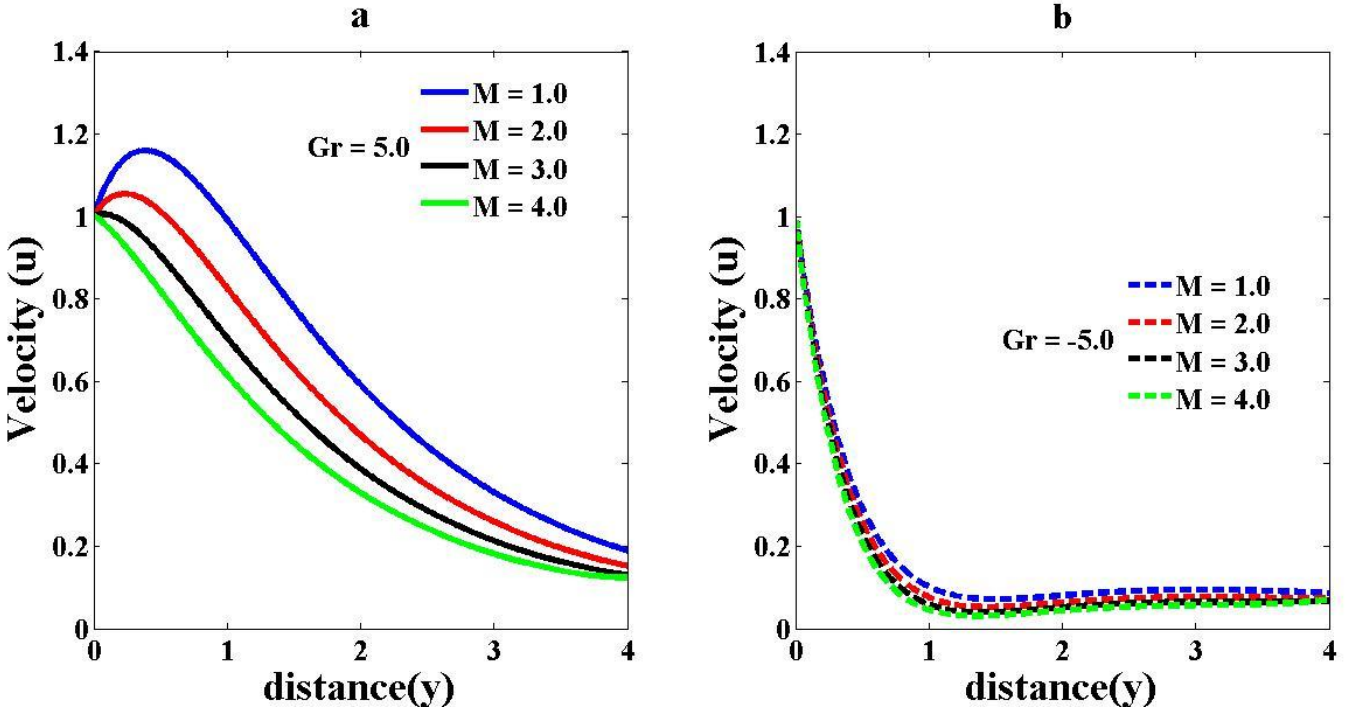

Figure 5: Effect of Magnetic field parameter $(M)$, on velocity $(u)$. 


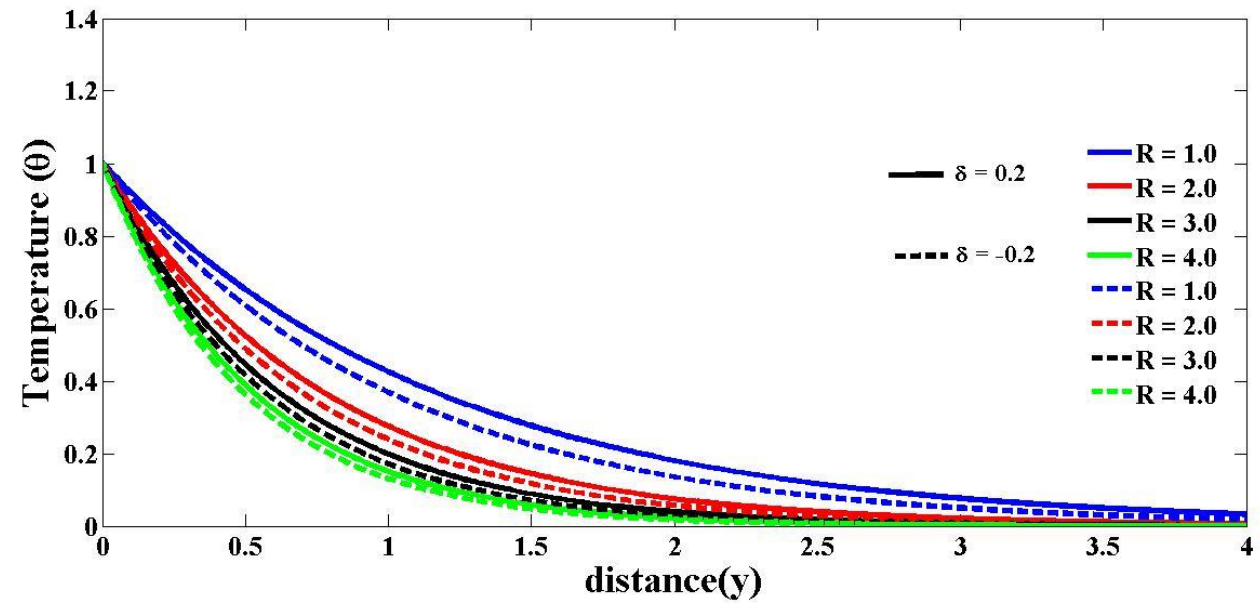

Figure 6: Effect of Radiation parameter $(R)$ on temperature $(\theta)$

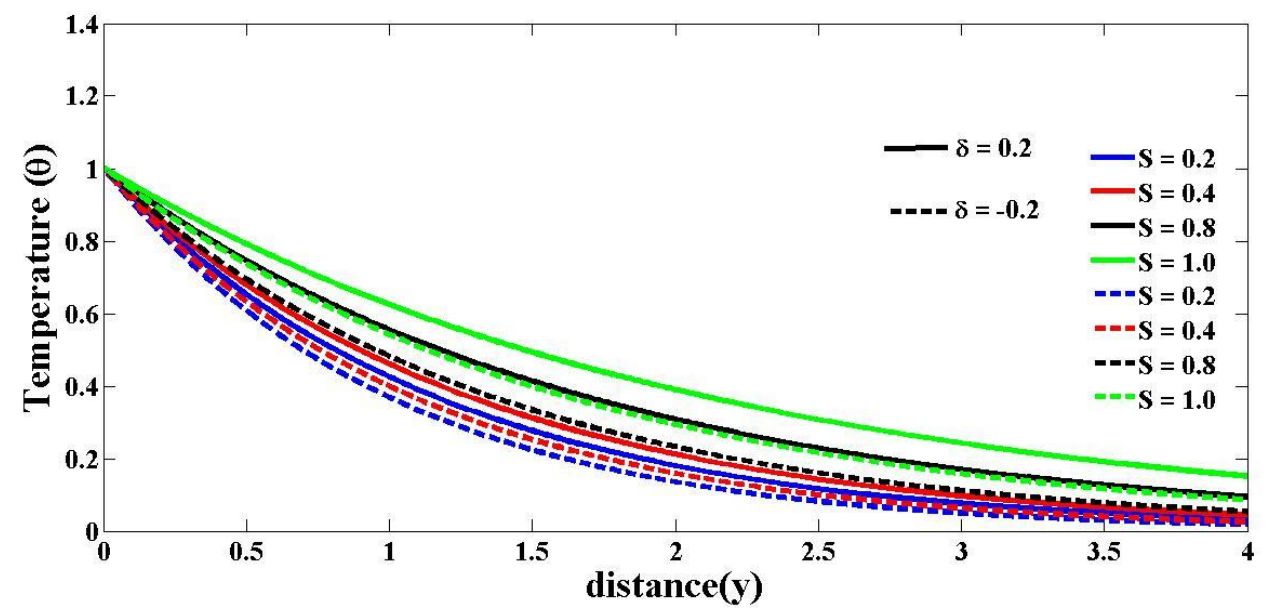

Figure 7: Effect of heat source parameter $(S)$, on temperature $(\theta)$

a

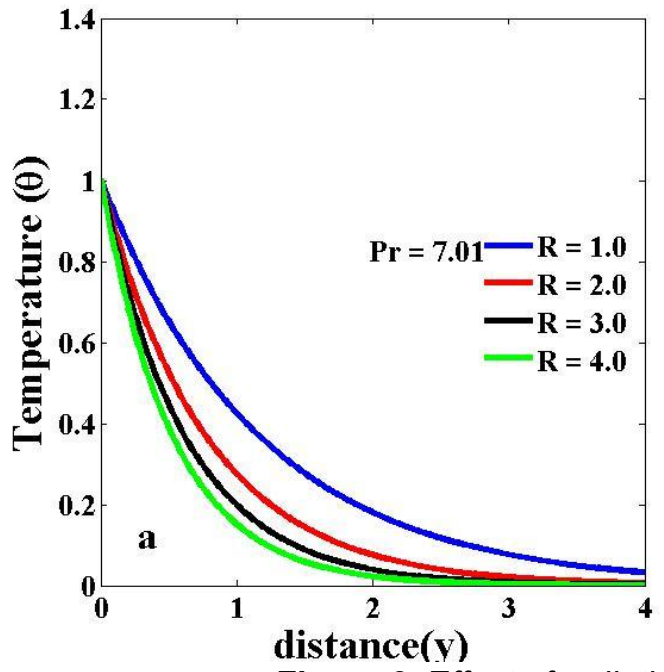

b

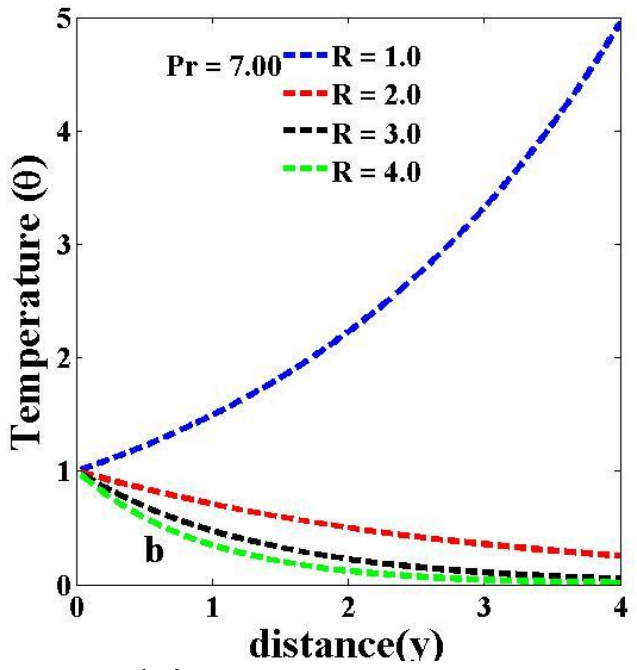

Figure 8: Effect of radiation parameter $(R)$, on temperature $(\theta)$. 
The comparison of variation of Skin friction $\tau_{0}$, Nusselt number $N u_{0}$ and Sherwood number $S h_{0}$ at $y=0$ is shown in Table 1. It is seen that increase Prandtl number (Pr), heat source parameter $(S)$, injection $(\delta>0)$, thermal Grashof number $(\mathrm{Gr})$, and sustention parameter $(N)$, enhances skin friction $\left(\tau_{0}\right)$, while increase in chemical reaction parameter $(R c)$, magnetic field parameter $(M)$, thermal radiation parameter

a

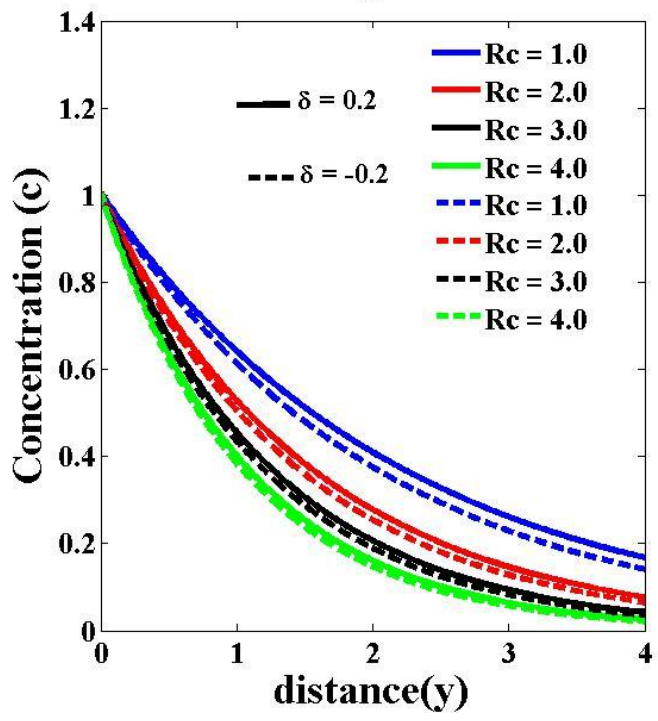

$(R)$, Schmidt number $(S c)$, and permeability parameter $(K)$, retard skin friction. It is noticed from the table that an increase in $\mathrm{Pr}, \mathrm{Sand} \delta$ decreases the rate of heat transfer and increase in radiation parameter $(R)$, increases the rate of heat transfer. Similarly, an increase in $R c$ and $S c$ enhances Sherwood number and reverse effect is observed when injection parameter is increase. Consequently increasing the variable pressure parameter shows no effect on rate of skin friction.

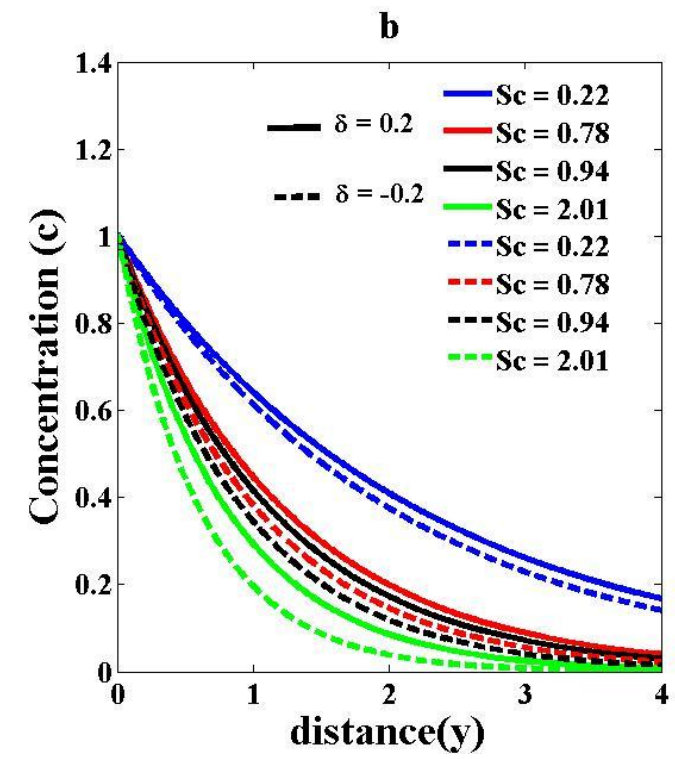

Figure 9: Effect of chemical reaction parameter $(R c)$, and Schmidt number on concentration $(c)$

Table 1: For Skin friction, Nusselt number and Sherwood number

\begin{tabular}{ccccccccccccc}
\hline $\boldsymbol{P r}$ & $\boldsymbol{R C}$ & $\boldsymbol{M}$ & $\boldsymbol{R}$ & $\boldsymbol{S}$ & $\boldsymbol{S c}$ & $\boldsymbol{K}$ & $\boldsymbol{\delta}$ & $\boldsymbol{G r}$ & $\boldsymbol{N}$ & $\tau_{0}$ & $N u_{0}$ & $S h_{0}$ \\
\hline 0.71 & - & 1 & 1 & 0.2 & 0.22 & 3 & 0.2 & 5 & 3 & 0.9638 & 0.8588 & 0.4480 \\
7.0 & - & - & - & - & - & - & - & - & - & 2.2113 & -0.3992 & - \\
- & 2 & - & - & - & - & - & - & - & - & 0.8805 & - & 0.6423 \\
- & - & - & - & - & - & - & - & - & - & 0.1154 & - & - \\
- & - & - & - & - & - & - & - & - & - & 0.9638 & - & - \\
- & - & - & - & - & - & - & - & - & - & 0.5254 & 1.8963 & - \\
- & - & - & - & 0.5 & - & - & - & - & - & 1.0106 & 0.7789 & - \\
- & - & - & - & - & 2.01 & - & - & - & - & 0.6870 & - & 1.2321 \\
- & - & - & - & - & - & 4 & - & - & - & 0.5034 & - & - \\
- & - & - & - & - & - & - & 0.5 & - & - & 1.0031 & 0.7664 & 0.4177 \\
- & - & - & - & - & - & - & - & 10 & - & 2.6543 & - & - \\
- & - & - & - & - & - & - & - & - & 5 & 1.7488 & - & - \\
\hline
\end{tabular}

\section{CONCLUSION}

The solution of thermal radiation and variable pressure effects of a viscous, incompressible and electrically conducting fluid between vertical porous medium is gained. In the absence of mass transfer equation [3] and $G r=N=M=K=S c==0$, our present result agrees with Jha et al. (2012). The 
dimensionless governing equations are solved analytically by perturbation method. The effects of various parameters were discussed. From the study it's concludes that:

i. Increase in thermal radiation parameter, Schmidt number, magnetic field parameter chemical reaction, decreases velocity, temperature and concentration.

ii. Thermal Grashof number increases the velocity.

iii. Thermal Grashof number $(G r)$, and sustention parameter $(N)$, enhances

\section{REFERENCES}

Chandra, R. N., Pada, G. B. and Kumar, S. L. (2014). Unsteady MHD Free Convection Flow Along a Vertical Plate in the Presence of Radiation Heat Flux. Scientific and Academic Publishing, 4 (3): $77-85$.

Das, S., Jana, M., Nath, J. R. (2011). Radiation Effect on Natural Convection Near a Vertical Plate Embedded in Porous Medium With Ramped Wall Temperature Open. Journal of Fluid Dynamics, 1: 111.

Das, U. N., Deka, R. and Soundalgekar M. V. (1966). Radiation Effect on Flow Past an Impulsively Started vertical Plate: An Exact Solutions. Journal of Applied Mathematics, 1 (2): 111-115.

Das, K. and Jana, S. (2010). Heat and Mass Transfer Effects on Unsteady MHD Free Convection Flow near a Moving Vertical Plate on Porous Medium. Bull Society Mathermaticians Benja Luka, 17: 15-32

Hossain, M. A. and Takhar, H. S. (1996). Radiation Effect on Mixed Convection along a Vertical Plate with Uniform Surface Temperature. International Journal of Heat Mass and Transfer, 31: 243-248.

Hossain, M. A., Alim, M. A. and Rees, D. A. S. (1999). The Effect of Radiation on Free Convection from a Porous Vertical Plate. skin friction $\left(\tau_{0}\right)$, while increase in chemical reaction parameter $(R c)$, magnetic field parameter $(M)$, thermal radiation parameter $(R)$, Schmidt number $(S c)$, and permeability parameter $(K)$, retard skin friction. It is noticed from the table that an increase in $\operatorname{Pr}$, Sand $\delta$ decreases the rate of heat transfer and increase in radiation parameter $(R)$, increases the rate of heat transfer.

International Journal of Heat and Mass Transfer, 42: 181-191.

Ibrahim, F. S., Elaiw, A.M., and Bakr, A.A. (2008), Effect of Chemical Reaction and Radiation Absorption on the Unsteady MHD Free Convection Flow Pass a Semi Infinite Vertical Permeable Moving Plate with Heat Source and Suction. Communications in non-linear Science and Numerical Simulation, 13: 10561066

Javaherdeh, K., Mirzaei, N. M. and Moslemi, M. (2015). Natural Convection Heat and Mass Transfer in MHD Fluid Flow Past a Moving Vertical Plate with Variable Surface Temperature and Concentration in a Porous Medium. Engineering Science and Technology an International Journal, 18: 423-431.

Jha, K. B., Samaila, K. A. and Ajibade, O. A. (2010). Unsteady Natural Convection Flow Between Infinite Vertical Parallel Plates with Ramped Temperature. International Journal of Energy and Technology, 2(10): 1-10.

Jha, K. B., Samaila, K. A. and Ajibade, O.A. (2012).Natural Convection Flow of Heat Generating/Absorbing Fluid near a Vertical Plate with Ramped Temperature. Journal of Encapsulation and Adsorption Sciences, 2: 61-68.

Kesavaiah, C. D., Satyanarayana, V. P. and Venkataramana, S. (2011). Effect of the 


\section{Nigerian Journal of Basic and Applied Science (June, 2019), 27(1): 48-58}

Chemical Reaction and Radiation Absorption on an Unsteady MHD Convective Heat and Mass Transfer Flow Past a Semi-infinite Vertical Permeable Moving Plate Embedded in a Porous Medium with Heat Source and Suction. International Journal of Applied Mathematics and Mechanics, 7 (1): 5269.

Kishore, M. P., Rajesh, P. and Vijayakumar, V. S. (2012). The Effects of Thermal Radiation and Viscous Dissipation on MHD Heat and Mass Diffusion Flow Past and Oscillating Vertical Plate Embedded in a Porous Medium With Variable Surface Conditions. Theoretical Applied Mechanics, 2 (39): 99-125.

Makinde, O. D. (2005). Free Convection Flow with Thermal Radiation and Mass Transfer Past a Moving Vertical Porous Plate. International communication in Heat and Mass Transfer, 32: 1411-1419.

Djam, Y. X. and Manjak, N. H. (2013). Analyzed effect of radiation on free convection flow due to heat and mass transfer through a porous medium bounded by two vertical walls analytically using perturbation technique. International Journal of Advanced Technology and Engineering Research, 3 (3): 120-125.

Mohamed, R. A. (2009). Double Diffusive Conviction-Radiation interaction on Unsteady MHD Flow over a Vertical Moving Porous Plate with Heat Generation and Soret Effect. Applied Mathematical Science, 3(13): 629-651.

Pal, D. and Talukdar, B. (2010). Perturbation Analysis of Unsteady Magneto hydro dynamic Convective Heat and Mass Transfer in a Boundary Layer Slip Flow Past a Vertical Permeable Plate with Thermal Radiation and Chemical Reaction. Communications in Nonlinear Science and Numerical Simulation, 15(7): 1813-1830.

Ramachandra P, V., Bhaskar R. N. and Muthucumaraswamy, R. (2013).
Radiation and Mass Transfer Effect on Two-dimensional Flow Past an Impulsively Started Infinite Vertical Plate. International Journal of Thermal Science, 46: 1251-1258.

Rout, R. B., Parida, K. S. and Pattanayak, P. H. (2014). Effect Radiation and Chemical Reaction on Natural Convective MHD Flow through a Porous Medium with Double Diffusion, Journal of Engineering Thermo-Physics, 1 (33): 53-65.

Singh, A. K. (1986). Effects of Heat Source/Sink and Radiative Heat Transfer on Hydromagnetic Natural Convective Flow Through a Vertical Channel. Computational Thermal Science, 2 (4): 323-332.

Sudheer, B. M. and Satya, P. (2009). Effects of the Chemical Reaction and Radiation Absorption on Free Convection Flow through Porous Medium with Variable Suction in the presence of Uniform Magnetic Field. Journal of Heat and Mass Transfer, 3: 219-234.

Ahmad A., Sarki, N. M. and Ahmad M. (2014). Radiation Effects on Heat and Mass Transfer over an Exponentially Accelerated Infinite Vertical Plate with Chemical Reaction. International Multiconference of Engineers and Computer Scientist, 11: 978-988. 